\title{
ENRAIZAMENTO DE ESTACAS HERBÁCEAS DE NESPEREIRA (Eriobotrya japonica Lindl) ${ }^{1}$
}

\author{
JOSÉ ANTONIO ALBERTO DA SILVA² \& FERNANDO MENDES PEREIRA ${ }^{3}$
}

\begin{abstract}
RESUMO - O cultivo da nespereira (Eriobotrya japonica Lindl) tem despertado interesse no Brasil, devido ao bom rendimento que proporciona aos produtores e à facilidade de comercialização. Com isso, cada vez mais se buscam métodos de propagação que preservem as características genéticas de interesse, induzam precocidade na formação da muda e no início de produção, além de baixo custo. O método de estaquia se adequa a estas características; sendo assim, o objetivo deste experimento é avaliar o efeito do tipo de estaca herbácea na produção de mudas de nespereira, num experimento conduzido na Faculdade de Ciências Agrárias e Veterinárias - FCAV/UNESP, Câmpus de Jaboticabal (SP), utilizando plantas matrizes de nespereiras, plantadas em 1977, da variedade Mizuho, pertencentes à coleção de plantas frutíferas da Universidade. Utilizaram-se estacas apicais herbáceas com e sem meristema apical, com 2 ou 4 folhas inteiras ou cortadas pela metade, num total de 6 tratamentos, 4 repetições e 12 estacas por parcela, em delineamento inteiramente casualizado. Após 120 dias do plantio das estacas em bandejas com vermiculita e mantidas sob câmara de nebulização, concluiu-se que a porcentagem de estacas vivas e a presença de calos foram significativamente maiores nas estacas apicais sem meristema e com quatro folhas inteiras, e não há efeito do tipo de estaca herbácea sobre o número de estacas enraizadas, número e comprimento médio de raízes. A presença de calos na base das estacas indica a possibilidade de estímulo natural de enraizamento que pode ser potencializada com a utilização de fitorreguladores.
\end{abstract}

Termos para indexação: propagação, estaquia, nêspera, calos, raiz

\section{ROOTING OF HERBACEOUS CUTTINGS OF LOQUAT TREE (Eriobotrya japonica LindI)}

\begin{abstract}
The loquat cultivation has been developing in Brazil, due to the good harvest and marketing. Propagation methods are looked for to preserve the good genetic characteristics, to induce precocity besides low cost. The cutting method has these characteristics, so a study was carried out at the FCAV/UNESP, in Jaboticabal, São Paulo State, Brazil, using loquat tree (Eriobotrya japonica Lindl), planted in 1977, Mizuho variety. It was used cuttings with and without tip-shoot, with 2 or 4 intact and cut by the half leaves, in a total of 6 treatments, 4 replicates and 12 cuttings/plot. After 120 days of the plantation of the cuttings in boxes containing vermiculite and maintained under an intermittent misting system, the percentage of survival cuttings and callus presence were significantly better in the apical cuttings without tip-shoot and with 4 leaves. There is no effect of the type of herbaceous cuttings on the number of rooting, number and medium length of roots. The callus presence indicates the possibility of natural incentive of rooting that can be increased by the use of growth regulators.
\end{abstract}

Index Terms: propagation, callus, root

A nêspera é uma fruta de clima subtropical, originária do Sudoeste da China e introduzida inicialmente no Japão e depois para outros países. Pertencente à família das Rosáceas, seu cultivo vem despertando interesse crescente principalmente no Estado de São Paulo, devido à maturação dos frutos que se dá nos meses de maio a outubro, quando a oferta de outros tipos de frutos é pequena, propiciando uma abertura de mercado com preços atrativos aos produtores.

Trata-se de uma cultura bastante exigente em mão-de-obra para práticas culturais, como as podas, desbaste de frutos, ensacamento e colheita. A planta necessita de temperatura média anual de $20^{\circ} \mathrm{C}$, é sensível aos ventos fortes, responde à irrigação e adapta-se bem a diferentes tipos de solos, desde que bem drenados (Penteado \& Junqueira, 1997).

As variedades mais utilizadas comercialmente no Brasil são Mizuho, Precoce de Itaquera, Precoce de Campinas IAC 165-31, Parmogi IAC 266-17 e Néctar de Cristal IAC 866-7. Já em outros países, encontram-se as variedades classificadas com polpa de coloração laranja: Big Jim, Early Red, Gold Nugget, Mogi, Mrs. Cooksey, Strawberry, Tanaka e Wolfe, e as variedades com polpa branca: Advance, Benlehr, Champagne, Herd's Mammoth, Victory e Vista White.

Segundo Penteado (1986), a variedade Mizuho é a de melhor aceitação no mercado consumidor brasileiro, com frutos grandes, formato oval-arredondado, coloração amarelo-alaranjada, película fácil de descascar, polpa delicada, fundente, sucosa, variando de bastante doce a mediamente ácida, com peso médio de 60 a $80 \mathrm{~g}$ e possuindo normalmente de 5 a 7 sementes. As plantas são vigorosas, com grande diâmetro e produtivas todos os anos. Os frutos devem ser ensacados, evitando assim manchas arroxeadas na epiderme.

Normalmente, a nespereira é propagada por enxertia tipo garfagem de topo ou "inglês simples" ou por garfagem lateral, sempre seguido da proteção do enxerto com um saco plástico para reter umidade, além de deixar 3 a 4 folhas na parte inferior do porta-enxerto, produzido a partir da germinação de sementes de nêsperas ou estacas enraizadas de marmeleiro (Cydonia oblonga Mill). A utilização de enxertia sobre cavalos provenientes de mudas formadas de sementes da própria nespereira resulta na formação de árvores de grande porte, inviáveis para o estabelecimento de um pomar comercial (Campo Dall'Orto, 1982).

A propagação de nespereira por estaquia tem sido pouco estudada, porém, dada à simplicidade, eficiência e produção de mudas em curto espaço de tempo que o método proporciona, tem tido larga aplicação na fruticultura (Pereira et al., 1997).

O presente experimento teve como objetivo determinar o melhor tipo de estaca herbácea de nespereira, visando à propagação a partir do enraizamento de estacas.

$\mathrm{O}$ experimento foi instalado e conduzido na Faculdade de Ciências Agrárias e Veterinárias-Fcav-Unesp, Câmpus de JaboticabalSP, localizada a $21^{\circ} 15^{\prime} \mathrm{S}$ e $48^{\circ} 18^{\prime} \mathrm{W}$, com altitude de $595 \mathrm{~m}$ e clima caracterizado como Cwa (Köeppen).

O material vegetativo foi coletado de plantas-matrizes de nespereiras (Eriobotrya japonica Lindl), plantadas em 1977, em plena produção, da variedade Mizuho e pertencentes à coleção de plantas frutíferas da Fcav, buscando ramos com brotações novas (do ano), com comprimento de $15,0 \mathrm{~cm}$ e diâmetro médio de $1,5 \mathrm{~cm}$, coletadas no período da manhã.

Logo após o corte dos ramos nas plantas matrizes no início

\footnotetext{
${ }^{1}$ (Trabalho 154/2003). Recebido: 17/10/2003. Aceito para publicação: 25/06/2004.

${ }^{2}$ Eng $^{\circ}$ Agr $^{\circ}$ Dr., Pesquisador Científico Estação Experimental de Citricultura de Bebedouro, jaas@ coopercitrus.com.br

${ }^{3}$ Prof. Dr., Depto. de Horticultura FCAV-UNESP-Jaboticabal-SP
} 
do verão, estes foram mantidos sob câmara de nebulização intermitente (10 segundos ligado e 65 desligado) sob ripado $(50 \%$ de sombreamento) e nestas condições manipulados, evitando a desidratação das estacas. Após o preparo, as estacas foram colocadas nas bandejas com vermiculita e mantidas na câmara (tipo ripado) com sombreamento de $50 \%$, por um período de 120 dias.

Destes ramos, prepararam-se as estacas herbáceas apicais com comprimento médio de $5,0 \mathrm{~cm}$, diâmetro médio de $1,0 \mathrm{~cm}$ e com 2 e 4 folhas inteiras ou cortadas ao meio, no sentido transversal, com o objetivo de diminuir as perdas de água. A base das estacas foi cortada em bisel logo abaixo de um nó ou inserção de folhas, enquanto o ápice foi preparado com e sem o meristema apical.

Utilizou-se de delineamento experimental inteiramente casualizado, com 6 tratamentos, 4 repetições e 12 estacas por parcela, totalizando 288 estacas, ou seja, 48 estacas por tratamento. Os valores de porcentagem de estacas vivas, com calos e enraizadas, foram transformados segundo arco-seno $\sqrt{x / 100}$, onde $\mathrm{x}$ representa o percentual obtido e, para a comparação dos resultados, foi utilizado o teste de Tukey.

A estaquia foi feita em bandejas plásticas perfuradas, utilizando vermiculita expandida de granulometria média, enterrandose a base das estacas a uma profundidade média de $2,5 \mathrm{~cm}$, seguindo metodologia descrita por Pereira (1983).

As avaliações após os 120 dias na câmara de nebulização intermitente para enraizamento constaram da identificação de estacas vivas e enraizadas, formação de calos, número e medição do comprimento das raízes.

Após as avaliações de enraizamento, as estacas foram transplantadas para sacos plásticos contendo a mistura de solo de subsuperfície (Latossolo), areia grossa e esterco de curral curtido na proporção $2: 1: 1$, e mantidas sob o mesmo sistema de nebulização intermitente durante uma semana, sendo em seguida transferidas para um ambiente tipo ripado (sombreamento de $50 \%$ ). Aos 30 dias após o transplantio, efetuou-se uma avaliação apenas para observar a sobrevivência das mudas.

A maior porcentagem de sobrevivência ocorreu no tratamento com estacas sem meristema apical, e com 4 folhas inteiras foi de $80,27 \%$. Já as estacas com meristema e apenas 2 folhas inteiras ou cortadas pela metade $(51,71$ e $46,73 \%$, respectivamente) resultaram na menor sobrevivência, diferindo significativamente (Tabela1).

Todos os tipos de estacas desenvolveram calos, indicando que ocorreu um estímulo ao enraizamento, com a mesma tendência da sobrevivência das estacas. As estacas sem meristema e 4 folhas inteiras apresentaram maior número de estacas com calos, enquanto aquelas com meristema e 2 folhas cortadas foram as com menores ocorrência, diferindo significativamente destas e das estacas sem meristema e com 2 folhas inteiras. Pereira et al. (1997) não obtiveram variações na formação de calos das estacas com folhas inteiras ou cortadas, porém as estacas apicais apresentaram maior formação de calos que as subapicais, contrastando com este experimento onde as estacas sem meristema apical, com 2 e 4 folhas, apresentam, em números reais, maior porcentagem de calos.

Segundo Fachinello et al. (1995), o calo aparece após o preparo das estacas, quando ocorre um lesionamento dos tecidos do xilema e do floema, resultando em posterior formação de um tecido de cicatrização, constituído por uma massa de células parenquimatosas, desorganizadas e em diferentes etapas de lignificação.

Apesar de muitos autores considerarem a formação de calos e raízes como processos totalmente independentes, Hartmann \& Kester (1990) afirmam que, freqüentemente, as raízes aparecem após a formação de calos, por meio da diferenciação das células parenquimatosas formadas deste.

Quanto à porcentagem de estacas enraizadas, não houve diferenças significativas entre os tratamentos, o mesmo se aplicando para o número médio de raízes por estacas e comprimento médio das raízes. Pereira et al. (1997) obtiveram um enraizamento significativamente superior para estacas com meia-folha em relação às com folhas inteiras, sendo mais acentuada quando as estacas eram provenientes da região apical.

Constatou-se que todas as raízes se originaram da base das estacas na região de inserção das folhas, próximo do local onde foi efetuado o corte em bisel.

A boa porcentagem de estacas vivas e calejadas indica um estímulo natural de enraizamento a qual pode ser potencializada com a utilização de fitorreguladores, ou a identificação de fatores internos que possam estar afetando o enraizamento, conforme citado por Fachinello et al. (1995).

Após as avaliações, as estacas enraizadas foram transplantadas para sacos plásticos com mistura de solo. Passados 30 dias, constataram que $100 \%$ das estacas transplantadas permaneciam vivas e iniciando a emissão de brotações.

Os resultados obtidos no experimento permitem concluir que a porcentagem de estacas vivas e a presença de calos foram significativamente maiores nas estacas apicais sem meristema e com quatro folhas inteiras, e não há efeito do tipo de estaca herbácea sobre o número de estacas enraizadas, número e comprimento médio de raízes.

FIGURA 1 - Estaca apical sem meristema e com duas folhas inteiras, enraizada e com brotação, Fcav-Unesp, Jaboticabal.

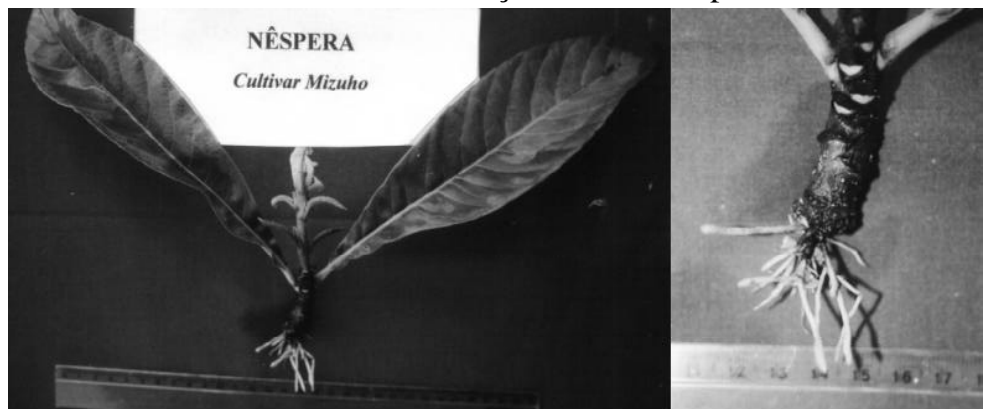

TABELA 1 - Porcentagem de estacas vivas, com calo e enraizadas, número médio de raízes por estacas enraizadas e comprimento médio das raízes de nespereira, após 120 dias, FCAV-UNESP, Jaboticabal-SP

\begin{tabular}{|c|c|c|c|c|c|}
\hline Tratamentos & Estacas vivas & Estacas c/ calos & Estacas enraizadas & $\begin{array}{l}\mathrm{N}^{\circ} \text { médio de } \\
\text { raízes/estaca }\end{array}$ & $\begin{array}{c}\text { Comprimento médio das } \\
\text { raízes }(\mathrm{cm})\end{array}$ \\
\hline 1. s/meristema, c/ 2 folhas & $68,16 \mathrm{ab}$ & $66,88 \mathrm{ab}$ & $8,67 \mathrm{a}$ & $1,10 \mathrm{a}$ & $1,25 \mathrm{a}$ \\
\hline 2. s/ meristema, c/ 4 folhas & $80,27 \mathrm{a}$ & $72,60 \mathrm{a}$ & $11,60 \mathrm{a}$ & $1,21 \mathrm{a}$ & $1,46 \mathrm{a}$ \\
\hline 3. c/ meristema, $\mathrm{c} / 2$ folhas & $51,71 \mathrm{~b}$ & $50,37 \mathrm{bc}$ & 8,67 a & $1,10 \mathrm{a}$ & $1,10 \mathrm{a}$ \\
\hline 4. c/ meristema, $\mathrm{c} / 4$ folhas & $60,83 \mathrm{ab}$ & $56,86 \mathrm{abc}$ & $13,51 \mathrm{a}$ & $1,25 \mathrm{a}$ & $1,22 \mathrm{a}$ \\
\hline 5. c/ meristema, c/ 2 meia-folhas & $46,73 \mathrm{~b}$ & $43,10 \mathrm{c}$ & $13,51 \mathrm{a}$ & $1,32 \mathrm{a}$ & $1,35 \mathrm{a}$ \\
\hline 6. c/ meristema, c/ 4 meia-folhas & $65,04 \mathrm{ab}$ & $58,05 \mathrm{abc}$ & $15,42 \mathrm{a}$ & $1,52 \mathrm{a}$ & $1,63 \mathrm{a}$ \\
\hline Teste F & $6,04 * *$ & $6,42 * *$ & $0,44 \mathrm{~ns}$ & $0,57 \mathrm{~ns}$ & $0,52 \mathrm{~ns}$ \\
\hline C.V. $\%$ & 15,73 & 14,58 & 70,33 & 32,81 & 39,59 \\
\hline
\end{tabular}

Médias seguidas de mesma letra não diferem entre si, pelo teste de Tukey, a 5\% de probabilidade.

Dados transformados em arc-sen $\sqrt{x / 100}$ 


\section{REFERÊNCIAS BIBLIOGRÁFICAS}

CAMPO DALL'ORTO, F.A. Marmeleiro (Cydonia oblonga Mill.) propagação seminífera, citogenética e radiosssensitividade - bases ao melhoramento genético e à obtenção de porta-enxertos. $161 \mathrm{f}$. Dissertação (Mestrado)- Escola Superior de Agricultura "Luiz de Queiroz", Universidade de São Paulo, Piracicaba, 1982

FACHINELLO, J.C. et al. Propagação de plantas frutíferas de clima temperado. 2. ed. Pelotas:UFPEL, 1995. 178p.

HARTMANN, H.T.; KESTER, D.E. Propagación de plantas - principios y practicas. México: Compañia Editorial Continental, 1990. 760p.

PENTEADO, S.R. Fruticultura de clima temperado em São Paulo. Campinas: Fundação Cargill, 1986. p. 133-142
PENTEADO, S.R.; JUNQUEIRA, W.R. Nêspera. In: Manual técnico das culturas. 2.ed. Campinas: Editora, 1997. p.267-73

PEREIRA. F.M. Enraizamento de diferentes tipos de estacas enfolhadas de goiabeiras (Psidium guajava L.) em câmara de nebulização. Científica, Jaboticabal, n. 11, v. 2, p. 239-44, 1983

PEREIRA, F.M.; ZANIN, E.S.; BARBOSA, J.C. Eficiência de diferentes métodos de propagação vegetativa da nespereira (Eriobotrya japonica Lindl.) em câmara de nebulização. In: CONGRESSO IBEROAMERICANO, 2., CONGRESSO IBÉRICO DE CIÊNCIAS HORTÍCOLAS, 3., 1997, Portugal. Actas de Horticultura ... v.15, p. 419-24 